\title{
An International Knowledge Building Network for Sustainable Curriculum and Pedagogical Innovation
}

\author{
Thérèse Laferrière (Corresponding author) \\ Faculty of Education, Laval University, 2320 rue des Bibliothèques, Université Laval \\ Québec, QC, G1V 0A6, Canada
}

Tel: 1-418-656-2131 ext. $5480 \quad$ E-mail: Therese.Laferriere@fse.ulaval.ca

Nancy Law

Faculty of Education, University of Hong Kong,

Pokfulam Road, Hong Kong, China

Tel: 852-2859-2540/28578540Ｅ-mail: nlaw@hku.hk

Mireia Montané

Director, Centre of International Educational Programs

College of Doctors and Graduates in Humanities and Sciences of Catalonia, Spain

Tel: 3-493-412-4907Ｅ-mail: mireia.montane@gencat.net

Received: January 26, 2012 Accepted: February 3, 2012 Online Published: May 8, 2012

doi:10.5539/ies.v5n3p148

URL: http://dx.doi.org/10.5539/ies.v5n3p148

\begin{abstract}
This paper presents the results of the first phase (2007-2009) of a design experiment, the Knowledge Building International Project (KBIP), in which K-12 teachers from several countries collaborate as a loosely coupled network of networks with a common goal — to implement technology-supported knowledge building jointly across their classrooms. There was a visible increase in agency at all levels of the network: students, teachers and school senior management, resulting in deepening levels of pedagogical innovation over time, as well as changes in governance in response to the innovation as a result of self-organization. These are emergent features characteristic of complex systems that cannot be explained by a traditional model of change as diffusion. This study adopts Banathy's dimensions for systemic educational design to identify the key features of the sociotechnical design that nurture and sustain the innovations upon which these teachers embarked within and beyond their own schools.
\end{abstract}

Keywords: Collaborative innovation, Collaborative learning, Ecological model of educational change, Sustainability, Networked classrooms

\section{Introduction}

Many policy makers believe that innovation is essential in a knowledge society. Nonaka and Takeuchi (1995) positioned innovation and knowledge creation as strategically important for business organizations and in the workplace. In education, innovators put forward 21st century skills as keenly important learning outcomes for school graduates. Scardamalia, Bransford, Kozma, and Quellmalz (2010) emphasize a developmental scheme that ranges from entry-level competence to competences characteristic of innovative groups in knowledge-creating organizations.

The notion of the classroom-as-a-knowledge-creation-organization is the underlying assumption here. Bereiter and Scardamalia (2003) have stressed knowledge building as an alternative concept to learning in the classroom. This paper presents the results of the first phase (2007-2009) of a design experiment inspired by their research advances, the Knowledge Building International Project (KBIP). Participating K-12 teachers from several countries co-designed the socio-technological environment for computer-supported knowledge building. The innovative pedagogical approach embodied in this project exemplifies how to enhance the learning environment in ways that would not be possible without the technology. The focus of this paper, however, is not on KBIP per se, but on 
understanding the key environmental characteristics and design features of the KBIP project that nurture and sustain the innovations upon which these teachers have embarked within and beyond their own schools.

Current models of educational change are often designed as "initiatives" to be piloted, refined and then scaled up through a process of diffusion. The KBIP project challenges this view, as it is an attempt to develop an ecological model of change that create conditions for productive interaction and collaboration across institutions and across countries. KBIP also supports self-organization by giving agency to teachers and schools to determine the pedagogical design for their own implementation of new practices. Such a model of change brings a much wider diversity of practices than many curriculum innovation initiatives that focus around specific pedagogical designs, resulting in an ecology of practices.

This study investigates whether there is evidence that such an ecological model of change creates conditions that are more conducive to sustainability than change instituted as "initiatives", and also describes the "ecological role" of an international network in the change process. In the first phase, we focus on the agency demonstrated by different participants as they developed socio-technical designs for engaging students in collaborative inquiry and knowledge building on climate change and sustainability related themes. In particular, we examine if there is evidence of the use of agency due to interactions between different participants in the network and whether the agency brings about co-evolution in rules and practices at school and system levels that are conducive to sustainability and institutionalization of change.

\section{Conceptual Background}

For Scardamalia and Bereiter (2006), knowledge building is an epistemological theory, a pedagogy and a technology. Knowledge building is the production and continual improvement of ideas of value to a community through collaborative inquiry. The knowledge building perspective focuses on developing classrooms as communities for progressive problem solving and knowledge creation. The goal of education underpinning knowledge building is thus very different from the prevalent knowledge centered curriculum adopted in most schools. There are 12 knowledge building principles that characterize the interactions and metacognitive focus of engagement for a knowledge building community: democratizing knowledge, community knowledge/collective responsibility, real ideas/authentic problems, improvable ideas, idea diversity, epistemic agency, constructive use of authoritative sources, knowledge building discourse, rise above, symmetric knowledge advancement, pervasive knowledge building, and finally, embedded, concurrent, transformative assessment (Scardamalia and Bereiter, 2004). Hence for teachers participating in the KBIP project, they have a commitment to change/improve the pedagogical design and nature of teaching and learning interactions in their classrooms.

Knowledge building is mediated by online discourse in the Knowledge Forum ${ }^{\circledR}(\mathrm{KF})$ software $(1994,2006)$, the design of which is founded on more than two decades of research on the processes of expertise and innovation. This research involved cognitive and computer scientists and practitioners. Social innovation (knowledge building) and technological innovation (KF) combined to be both central to the classroom agenda. This software consists of a web-based collaborative platform for extending and deepening classroom discourse, and includes scaffolds to support written discourse as well as a set of analytical assessment tools that participants and classroom-based communities can apply to monitor their own knowledge building activity.

Influenced by this perspective, an international network of researchers, practitioners and education policy makers evolved gradually over a period of more than a decade, scaffolding as well as building on the pedagogical and research activities conducted within interconnected local university-school-government partnerships (Laferrière, Montane, Gros, Alvarez, Bernaus, et al., 2010). KBIP (2007-2009) is a recent phase of this international network, inspired by literature on educational reform and innovation, in addition to theoretical advancement and school success in knowledge building. Knowledge building applied to schools is a principle- and computer- based innovation.

Complexity/ecological/adaptive models for understanding innovation are still in their beginning stages. Banathy's (1991) systemic framework was chosen for identifying the following dimensions of socio-technical designs: patterns of interaction, focus of the inquiry, and scope of the inquiry. Since the beginning of the 1940's, socio-technical design has been used by London's Tavistock Institute for Human Relations to refer to the participation of end-users in the design and integration of information systems in the workplace in order to make system-based work more satisfying and rewarding (Scacchi, 2004). A "socio-technical interaction network" is an outgrowth of user participation in the design of an educational system that integrates computers, especially Internet-based tools. Reinvention is the shared goal, and participants constantly seek to discover new ways of establishing work practices (Scacchi, 2004). Complex systems and educational change may be studied by applying concepts and procedures derived from the study of other complex dynamical systems (Axelrod and Cohen, 1999; Engeström, 1987, 2001; 
Kaptelinin, and Nardi, 2006; Lemke and Sabelli, 2008). Their perspectives fit with systemic change. Banathy's (1991) systemic framework is very basic (see Figure 1), and is adopted for studying agency in developing socio-technical designs for knowledge building and inquiry during the period 2007-2009.

Insert Figure 1 about here

Based on Banathy's dimensions (1991), we conducted analyses of the innovation at different levels of the hierarchically nested education system: classroom, school, school district, and ministry of education. The following research questions pertaining to each of the three dimensions were asked in order to explore whether there was evidence of sustained interaction, extended agency and co-evolution across boundaries at different levels or locations:

- Dimension one: patterns of interaction. What were the characteristics of the relationships between agents from within and across educational systems and of key processes such as information exchange, cooperation, coordination, and integration?

- Dimension two: focus of inquiry. At which level(s) of the system was agency observed: learning, teaching, administration, or governance?

- Dimension three: scope of the agent's inquiry. Were agents active within the boundaries of their level in the existing educational system? Did agents broaden the boundaries in order to consider issues and concerns in the educational (ecological) environment during the project process?

\section{Methodology}

The authors have been centrally involved in leading three of the most active sites in the KBIP project. In fact, they have also been leading the local professional network of Knowledge Building (KB) teachers at each of these three sites. These three networks are supported with government funding to improve the quality of education through adopting a knowledge building (KB) approach and using the Knowledge Forum ${ }^{\circledR}$ online platform. Research and development in the form of design-based research are ongoing in the three sites. In conducting this study, the authors agreed on the framework and methodology for analyzing the features of the KBIP developments at each site, and took responsibility for analyzing the observations at their own respective sites. Their collective assessment is derived from their site-based analyses.

\subsection{Sites, Agents, and Tools}

In Barcelona, the International Office of the Ministry of Education exercises leadership in Catalunya (Spain) and in Europe regarding classroom activities that foster knowledge creation as an ongoing activity of school learners (see http://www.xtec.cat/ofinternacional/COMconeixer/eng/index.html). In Hong Kong, the Knowledge Building Teacher Network (KBTN, http://kbtn.cite.hku.hk) is structured as a school-university partnership program with funding support from the government to develop a knowledge building pedagogy in schools. In particular, a community of knowledge building teachers has made significant progress in developing a model of professional development support for scaling up curriculum and assessment innovation in schools, and in establishing sustained collaborative inquiry among a network of knowledge building classrooms in three continents. In Quebec (Canada), the Remote Networked Schools (www.eer.qc.ca) project led by CEFRIO, a knowledge transfer organization, involves over 100 schools and 23 school districts. Its focus is on providing a quality learning experience for remote school students. Online collaboration tools (KF and iVisit) are used to improve the learning environment by engaging students in collaborative inquiry and knowledge building within and across classrooms, schools, and school districts.

The common core activity at each of the three sites (Catalunya, Hong Kong, Quebec) was centered on the understanding of the knowledge building principles for engaging students in knowledge building. Participants (students, teachers, school principals, ministry personnel, university teacher educators and researchers) used KF as a "collaborative space" (asynchronous online discourse) with school learners, and among themselves. For synchronous discourse, a multi-user web-based videoconferencing system (VIA) was used. There was a growing local network for deepening and extending the knowledge building pedagogical innovation in each of the sites. KBIP (2007-2009) arose out of spontaneous expressions of interest from teachers, during interactions at conferences and supported by university-based researchers and government policy makers. The idea was to link students in classrooms across different sites to collaboratively participate in knowledge building on problems of international importance. The project was also conceived as a mechanism to support knowledge building among teachers and researchers across the different sites.

The focus of the students' learning activities was on understanding and tackling climate change. Students wrote hundreds of contributions on $\mathrm{KF}$ and over twenty desktop videoconferences were held among collaborating 
classrooms. School personnel and ministry officers provided guidance and encouragement regarding curricular requirements, while university teacher educators and researchers conducted onsite and online professional development workshops.

Participation in KBIP was voluntary and fluctuated according to local circumstances. There were people who provided support in the background, and some who declared themselves interested in engaging their students in KBIP but did not do it for either technical or time-related issues. Only those who engaged in online interaction are counted in Table 1, which is indicative of the scope and diversity of the network during the 2007-2009 period.

Insert Table 1 about here

\subsection{Analytical Procedures}

The agency of participants was analyzed using Banathy's framework. We investigated the focus and scope of agency at each site, as well the presence of patterns that connected participants within and between sites. We gathered vignettes and descriptive statistics. Vignettes are meant to capture special moments in the life of the network, and give the reader a sense of the dimensions (focus, scope, and patterns) of this socio-technical design. Vignettes were prepared by an external observer invited to transcribe what he saw online (KF and VIA), and selected through inter-observer and intra-observer agreement reliability.

Understanding the interactions between components in a complex system is the key to understanding its characteristics and development. Agency at all levels was key, and participants demonstrated agency as they developed socio-technical designs for engaging students in collaborative inquiry and knowledge building on climate change and sustainability related themes. Hence we begin by analyzing the nature of the interactions that took place between agents from within and across educational systems and, using Banathy's framework, we examine whether the interactions were information exchange, cooperation, coordination or integration.

The collective agency of learners in knowledge building classrooms in the different network sites was evidenced by analyses of online written discourse (Law, Yuen, Wong, and Leng, 2011; Laferrière and Lamon, 2010). In this study, we analyze 1) the patterns of interaction according to Banathy (information, cooperation/collaboration, coordination, and integration), 2) the agency for inquiry as observed in the KBIP according to his four foci of inquiry (learning, teaching, administration, and accountability/governance) for a design process to unfold successfully, and 3) the scope of the agents' inquiry - within and beyond the boundaries of local classrooms, schools, school districts, environments, (networked) communities, and societies. Our assumption is that unless increasing levels of agency exercised at all dimensions of an educational system are observed to take place simultaneously as dynamically linked events, it is unlikely that the change will be sustainable. We seek evidence through online observation, participants' notes, and interviews with teachers.

\section{Results}

\subsection{Patterns of Interaction}

Before KBIP, researchers, practitioners and policy makers from the different sites had opportunities to interact during annual conferences on knowledge building. However, these were primarily opportunities for information exchange and only had low levels of impact on the organization and practices in the different sites. KBIP took off as a result of some teachers' suggestion to build collaborative knowledge building activities among classrooms in different countries and the support given to such suggestion by the local networks in the three sites.

\subsubsection{Collaboration Online}

Implementing KBIP required cross-site cooperation and collaboration not only among learners, but also among the teachers.

Among learners in different sites. Classrooms invited other classrooms to work in their online space on a specific problem. A number of strategies appeared: 1) open invitation to enter the online space of one's classroom, and response to written notes; 2) visit of another classroom's space, and writing in one's own classroom space; 3) preparation of a rise-above note to be translated and put into a third space. However, these moves remained challenging for most classrooms, and most classrooms ended up sharing their work during videoconferences using PowerPoint presentations.

Among teachers in different sites. Teachers engage in the co-design of procedures for facilitating knowledge building activities at each site and organization of the collaborative aspects of these activities such that they become an integral part of the students' learning experience. They learned from one another, and a critical mass of classrooms engaging in knowledge building was constituted. This collaboration took place via KF® and VIA. 


\subsubsection{Coordination}

To implement the collaboration also required much coordination - across sites as well as within individual sites, and included scheduling of synchronous events, time management and support.

Time scheduling. It was easier for elementary teachers than for secondary school teachers to find time for inquiry. The latter felt the time constraints of less flexible school schedules. School principals facilitated teacher agency regarding time management by allowing teachers to switch teaching periods with other colleagues, conduct activities outside class time, and cumulate work time that they could later negotiate to other means.

Time management. Teachers provided opportunities for collaborative inquiry during class time. Some elementary teachers and their students engaged in this activity for an hour on a daily basis, some devoted a few intensive weeks, and others gave students minimal amounts of time. School teachers from Hong Kong tended to assign the students' work on KF to be accomplished as home-work, but would conduct the knowledge building facilitation, including discussing the online written discourse in class. Both elementary and secondary school teachers from Catalunya had their students stay after school to allow for synchronous verbal conversations (web-based videoconferences) with Quebec students.

Support. School principals provided technical and emotional support in a number of ways: They ensured that the equipment would be functional and they explained to parents the teachers' pedagogical goals for conducting the learning activities. Catalunya and Hong Kong' school principals encouraged teachers to engage students in collaborative inquiries. Many principals were present during videoconferencing sessions. A Quebec school principal provided translation during videoconferences.

\subsubsection{Integration}

For the KBIP activity to take place during the school year, interactions are required to achieve integration of the knowledge building work into the formal school curriculum.

Theme with local resonance. Teachers who engaged students in knowledge building facilitated authentic questioning on the general theme of climate change and sustainability. They reinforced students' questions and ideas that could be transformed into a problem for which local data could be generated.

Seamless onsite/online conversation. Teachers synthesized questions and students' interests expressed verbally into a written online formulation of a problem, or encouraged a student or a team of students to do so. At other times, the inquiry began with students asking questions online, and the teacher followed through by referring to the online question(s) during classroom verbal interaction.

Summarizing our analysis, we found that KBIP acts as a boundary object, that is, an object that acts as interface between communities: It scaffolds interaction at all three levels beyond information exchange - collaboration, coordination and integration. In the following section, we will examine the impact these rich interactions bring about in relation to agency for the knowledge building innovation at all four foci of inquiry: learning, teaching, administration and governance.

\subsection{Agency for Inquiry}

\subsubsection{Learners}

The opportunity to collaborate online in knowledge building, both on KF and VIA videoconferencing created a very different sensitivity to what students may experience and consciousness of what they can do. Here is an excerpt of what an external observer wrote after a videoconference involving elementary classes from the three countries:

« Néih hóu! » « Bona Tarda! » « Bonjour! »

Those salutations, spoken by the Hongkongers, Catalans and Quebecers mark the overture of the online classroom. We decide upon the rules of the procedures for the conference. Christian proposes candidly: "Why not alternate between continents?" - in a regular classroom, he would have asked: "Why not take turns?" While everybody casually agrees, I am left speechless with astonishment: alternate between continents?! Upon hearing those words, I instantly realize the ease with which the KBIP team removes any notion of distance, frontiers and geographical barriers from their new strategies of education. Thanks to their efforts, students from everywhere around the Globe now have the opportunity to discover foreign people by interacting amongst each other in a lively relationship. But online classrooms are more than just chatting with people from around the world: it's about forging solid intercultural bonds by working together towards a common goal; it's about a collective thinking process built from one student's background, and enriched with the international cultural diversity provided by each classmate and teacher. 
The opportunity to connect with other students from widely differing cultures located on the other side of the globe released a level of energy and agency that is seldom seen even in knowledge building classrooms not involving international collaborators, as is illustrated in the following vignette from the same observer's notes:

After this intervention by the kids of Labelle, we move on to a Catalan teacher who provides us with a summary of all the research conducted by her students during the last few weeks. Upon completing, she immediately hands the microphone to a few youngsters from her class. With a contagious enthusiasm, the Catalan children offer us a most lovely panorama of the Catalunyan woods, accompanied by a speech that they have prepared in their native language. In spite of being born less than a decade ago, the kids seem enthralled by a national pride for those forests that are enrooted in their collective minds as natural and historical jewels. The kids mark the closing of their speech with a sound ecological thought about love and nature. With a most diplomatic intent, they invite a school of Quebec to present their own boreal forests. The school of Quebec thus carries on with a series of scientific facts that contrasts wonderfully with the poetic strength of the Catalans. I am enchanted by the duality of the two exposés: after such a marvelous succession of the Mediterranean artistic approach and the American empiricism, who could doubt any longer, the abstract idea of cultural diversity?

The videoconferences reported in the above two vignettes were held after the classes had been collaborating asynchronously to work on a common problem on KF for some time. At each site, a specific local server was used to support online work on KF with the interface in the local language. For the classrooms that had opted to participate in KBIP, students and teachers had to conduct their collaborative work on a server located at one of the sites with an English language interface set up for KBIP. Students had to learn how to access the server, find the new collaborative space, translate into English their rise-above notes (summary notes) on work they had done earlier within their own class into English and post in the collaborative space. They would then need to read the many notes posted by others before embarking on the joint knowledge building work in this new space. Students demonstrated extra motivation as they conducted knowledge building with other international classrooms.

Throughout the 2007-2009 period, Catalunya, Hong Kong and Quebec students repeatedly brought data demonstrating that their local environments were experiencing some changes: city-sponsored bicycle renting in Barcelona as a response to pollution, and erosion on the St-Lawrence River. In spring 2008, Hong Kong and Quebec students came to realize that that there are common challenges and issues even when the physical environments might be different - e.g. water pollution and sedimentation - in tropical coastal waters and in temperate fresh water lakes. This led some students to become more interested in learning how people at the other site tackle their environmental problems since their strategies could also be relevant to students' local situation. At times, the students took on issues on a broader scale such as the sustainability of endangered animals like polar bears, turtles or birds.

At the end of summer 2009, students from Catalunya and Hong Kong went to Mallorca to study the effects of tourism on the sustainability of the limestone caves. They took the initiative to conduct research on the caves and they identified questions for exploration before arriving in Mallorca. They were introduced to an expert on caves from the local university who could answer the questions they raised. Initially, the expert told the students that there was no problem with respect to the sustainability of the caves since the concentration of carbon dioxide from humans visiting the caves would only have a negligible impact on the stalactites and stalagmites growing in the cave. However, the students were not satisfied with the expert's explanation and thus took ownership of searching for evidence of the environmental impact of human activities. During the visits to the caves, they made many pertinent observations. For example, some students noticed the growth of green moss around areas where lighting was installed to guide visitors. They also saw a bat moving after being disturbed by the noise made by visitors. Furthermore, some students noted the presence of a spider in a corner and came to the conclusion that there must be other living things around which spiders could eat. After the visit, they further discussed the meaning of the sustainability of caves and concluded that the preservation of caves should not only focus on the physical structure but must also take into account the ecological environment of the caves. The expert was so impressed by the earnestness of the students' inquiry that he remarked afterwards that these young children were better learners than some of the university students that he taught. Each of the students who took part in this activity, whose age ranged from 9 years to 16 years, contributed to a presentation of the results of their collaborative inquiry to 300 teacher educators in a plenary session of the annual conference of the Association for Teacher Education in Europe, which took place concurrently in Mallorca.

The above examples show an increase of learners' agency as KBIP unfolded. The students' sense of motivation and responsibility increased as they decided what they needed to understand and how they wanted to conduct the inquiry. With the students' increasing agency for their own learning, there is also clear evidence of students' learning 
outcomes in knowledge, communication and collaboration skills, global awareness and sensitivity, technological fluency as well as sense of community and global responsibility.

\subsubsection{Teachers}

While the teachers were gradually releasing control of the learning goals and processes to the learners, they were assuming a different kind of agency to actively guide their students through the process of collaborative inquiry. First, the teachers manifested their agency by showing interest in having their classrooms collaborate during the 2007 Knowledge Building Summer Institute held in Toronto. In summer 2008, the Tomorrow's Innovators (TI) program, which was part of the Summer Institute and involves bringing children from the different sites to conduct authentic inquiry in situ, was primarily designed by university researchers and assisted by teachers and graduate students in its implementation. In summer 2009, the TI program was primarily designed by teachers and supported by university researchers. Since September 2009, teachers have expressed agency to initiate liaison, coordination and integration, organizing VIA videoconferences, and even mini-Tomorrow's Innovators programs (mini-TIs) in which students from one site travel to the other to conduct joint field work and exploration that build on their earlier online knowledge building work. In 2009-2010, two mini-TI programs joined Hong Kong with Singapore schools and Hong Kong with Barcelona schools. The organization of these programs were carried out entirely by the teachers, with support from the administration of the schools involved. These developments clearly demonstrate that there is increasing teacher agency, making it possible for the patterns of interaction to move from cooperation to integration. The emergence of integration is intertwined with increasing teacher agency, and it is a journey of dynamic interaction within and between the different levels of the education ecology - often referred to as stakeholders in the educational change literature and labeled as focus of inquiry in Banathy's (1991) framework. The nature of this journey is briefly described below.

Distributed but persistently difficult coordination. At first, at each site, collaboration was mediated by a member of the researcher-led or government personnel-led partnership (depending on the local context) who maintained frequent online contacts with the others. Then, teachers who can speak English as a second language took responsibility for the coordination of activities across sites. However, translation remained a problem and posed a constraint on the level of engagement for those who do not speak English, often resulting in missed opportunities. Those teachers who could speak English translated on many occasions before and during videoconference meetings, thus allowing their colleagues' classrooms to communicate with classrooms from other sites. As teachers exercised leadership, distributed coordination appeared. This was a sign that the sustainability of KBIP was no longer resting on the shoulders of the initiators of the partnership. However, time management across classroom schedules and time zones as well as school and civil calendars remained a challenge. Students were disappointed when another classroom did not respond quickly to their questions and ideas written on KF, and let alone the fact that not all questions were interesting ones to answer for students invited to join another classroom's KF database. Other problems encountered included a partnership between classes lost over a rearranged schedule, teachers' unplanned leaves of absence, and difficulties for students to communicate in the English language. Debriefing of online meetings became increasingly important for teachers seeking to move beyond such hurdles.

Resilient cooperation (cross-site collaboration). In order to achieve a successful videoconference during which classrooms presented their school and culture, or local environmental sustainability challenges as a result of their collaborative inquiry supported by KF, much co-planning was required. At the beginning of the 2007-2009 period, teachers and school principals were invited to attend online meetings but it was the government/researcher partnerships that led the planning process. Decisions were made with regard to the KBIP calendar of events and the specific KF server to be used for international collaborative inquiries. In between videoconferencing meetings, many exchanges took place through email with the purpose of exploring and securing cooperation between two or three classrooms. Increasingly, teachers manifested agency in making contact with a potential cooperating teacher. Today, there are some teachers who have collaborated for more than two years with one another to engage their classes in joint collaborative inquiries. These teachers are now taking the lead to help other interested teachers new to KBIP by setting up international collaboration among clusters of KBIP schools in each location. They have become the lead persons for local school clusters, each comprising a few schools sharing the same inquiry problem, and have taken on voluntarily the responsibility to liaise with similar clusters led by their collaborating counterparts in the other site. However, the KBIP calendar of events remains an ongoing work in progress. Late changes must be accommodated as nobody wants to deceive students who have been preparing their presentation, and who want an audience. At times, the partner class could not present itself at the meeting, and last-minute special guests filled in (e.g., university students, government aides, or school principals with a few students). 


\subsection{Administration}

The scope of KBIP called for agency at all administrative levels, within and beyond familiar boundaries.

\subsubsection{University-School-Government Partnership}

University researchers interested in the design of networked learning environments as design research (Collins, Joseph, and Bielaczyc, 2004) and, therefore, in innovation and change, made several valuable contributions at the onset of KBIP. They first introduced local teachers and school principals to knowledge building. They suggested through collegial professional development activities ways to "administer" the knowledge building approach in the school curriculum. As in other design researches, they devoted time not only to research, but also to intervention, including instruction on the basics of the knowledge building pedagogy and individual guidance to more advanced teachers in the practice of this pedagogy. In Quebec, a fourth partner was involved, CEFRIO, a center that facilitates research and innovation in organizations using information and communication technologies (ICT).

\subsubsection{Release Time for Teacher Co-Learning and Professional Development}

As the project developed, the partnership project leaders included in their research proposals release time for teachers wanting to get involved in KBIP. In Quebec and Hong Kong, analyses of online written discourse were integrated into professional development workshops and meetings with teachers who showed increased interest in participating in the project. The teachers requested such analyses in order to gain a clearer picture of their students' progress in their written discourse and consequently refine their interventions. The activities of these teachers as agents of change clearly moved them to new levels of professional practice.

\subsubsection{Voluntary Participation in the KB International Network}

Agency requires self-determination, freedom to choose and innovate. Volunteer teachers who saw the possibility to offer their students rare opportunities to grow and at the same time to develop professionally by exploring and understanding knowledge building, were the ones who took the initiative to engage themselves and their students in collaborative inquiries. New challenges also awaited students, including their assumption of what learning is and how learning takes place. In fact, knowledge building is different from learning as the classroom-based community moves beyond the current body of knowledge held separately by individual members of the community to deeper levels of collective knowledge shared by the entire community. For this to happen, classroom organization and management need to operate in participative/democratic modes.

\subsubsection{School Administration in a Boundary Spanning Context}

School leaders in the KBIP schools were challenged by new learning experiences with respect to their professional relationships with researchers and colleagues. School principals (one from Hong Kong, three from Catalunya and one from Quebec) soon recognized that KBIP teachers were involved in a form of professional development that combine theory and practice. In some schools in all three sites, the principals also recognized the value of knowledge building and the need to modify the curriculum and staffing structure to support and strengthen knowledge building in the school curriculum. Some school principals got directly involved in the pedagogical process while other school administrators exercised agency by staying close to the action and/or reflecting on the process. They contributed to the smooth administration of the KBIP project by modifying/relaxing administrative restrictions and facilitating school level changes on teaching related matters.

As patterns of interaction diversified and evolved within KBIP, role shifting was observed: teachers/school principals took on coordination roles in Catalunya and began interacting with teachers/ school principals in Hong Kong; Quebec graduate students speaking different languages acted as mediators between teachers. Two or three people from each site acted as nodes in the network: they were the ones most present, most often called upon or referred to, and who brought continuity in the ever changing network. All these people virtually "entered" the school(s) that the school principals and other administrators were managing.

\subsection{Accountability and Governance}

In any institution, governance structures and practices are established to ensure that the organization is managed effectively and efficiently to achieve the institutional goals. However, as a result of such actions, governance often works against innovations that attempt to bring about fundamental changes to the goals or processes of the institution. For innovations to be sustainable and become institutionalized, changes in the governance are often necessary. In the KBIP project, we have also observed many instances in which difficulties encountered can be traced back to the governance at various levels of the education system, which is not surprising. Examples of governance constraints include timetabling constraints, accountability systems, etc. What we are interested in 
reporting here are observations of how KBIP activities have brought about some preliminary changes in governance (or at least the strength or power of the governance) at several levels in the three sites.

\subsubsection{From Content-Driven and Teacher-Centered Instruction to Student-Centered Inquiry-Focused Learning}

Teachers in the knowledge building networks often face competing demands on their teaching practices. While the education reform rhetoric about the need to develop students' $21^{\text {st }}$ century skills gives legitimacy to knowledge building as a preferred pedagogical approach, the use of system-wide assessment on well defined curriculum content as key mechanisms for quality assurance poses serious pressure on teachers to not take the risk of encouraging students to undertake open-ended explorations. In addition, engaging students in authentic questioning and releasing their agency for rigorous information and local data gathering in cooperation with another teacher doing the same jointly in parallel classrooms demands subtle time management and leadership on the part of the teacher. In our study, KBIP provided teachers with a legitimate context to deviate from the normal curriculum as exposure to and collaboration with international peers were generally seen as important learning experiences for students. In one such school in Hong Kong, the school leaders witnessed the depth of engagement and the level of questioning and understanding reached by the students within KBIP contexts. Their observations increased the participation of the teacher and students at the classroom level governance and provided room for the teacher to deviate from the tight content specific curriculum expectation towards more open-ended inquiry.

During the first year, it was rare for the cooperating classes to have concurrent research questions and time schedules. Nevertheless, classes visited each other's views on the KF databases and added relevant content. Almost all classes had something to present at videoconferences held towards the end of the first or second semesters but there were different levels of content shared in terms of the depth of inquiry. For the second and third meetings, teachers had clearer expectations and were more prepared to facilitate student inquiry, and to communicate with each other to plan their joint efforts accordingly. Joint inquiries leading to the formulation of new questions requiring further inquiry remained the exception. When such joint activities occurred, both classrooms developed their thinking within the same database, and were quite excited to see, listen and talk to their peers online during a videoconference held privately or open to a third or a fourth classroom.

4.4.2 From a Standard-Driven, Tightly Specified, Whole Grade Lockstep Curriculum Progression to More Flexible Curriculum Design and Implementation That Can Be Adjusted Based on Students’ Interests and Progression

The governance in relation to curriculum and pedagogical decision-making within a school is not easy to change and is often a constraining factor or even an obstacle to teachers' efforts to innovate. School $\mathrm{H}$ is a school in Hong Kong where decisions on topics ranging from the curriculum delivered annually to the content taught weekly are made by the subject panel and must be followed by all teachers. Furthermore, there are regular tests of students' achievement every few weeks, making it extremely difficult, if not impossible to create a learning environment that encourages student agency and inquiry. In spring 2009, the government official leading the KBIP project in Catalunya was invited by the Hong Kong KBIP network to visit Hong Kong in order to give professional development seminars, visit schools and meet other government officials. The school principal and the academic advisor of the school board joined the class observation when the Catalunyan official visited School $\mathrm{H}$ to observe the knowledge building classroom in action. There was only one KBTN teacher, teacher T, in the school at that point, teaching the subject General Studies. Both the Catalunyan visitor and the school leaders were very impressed by the questions raised by the students and their demonstrated depth of engagement. The academic advisor of the school (an honorary appointment made by the school board to a retired school principal serving on the board) who was initially not familiar with the KBIP project was particularly impressed by the strength of knowledge building as a pedagogical approach and commented that this form of teaching is what the whole school should aspire to implement. Subsequent to the visit, the school principal, in consultation with the academic advisor, made arrangements for one grade level to be an experimental grade for knowledge building in the General Studies subject and assigned two other teachers interested in experimenting with knowledge building to work with teacher $\mathrm{T}$ in this school level experimentation. This was in fact a very small step, but a significant one, in modifying the school governance on curriculum implementation to allow for flexibility as well as teacher and student agency.

\subsubsection{From Voluntary to Mandatory Participation at the School Board Level}

Participation in KBIP led to impressive results highlighted in the last report of the researchers of the Remote Networked School (RNS) project (Laferrière, Hamel, Allaire, Turcotte, Breuleux et al, 2011). The RNS model, characterized by the use of collaboration tools (KF and videoconferencing between peers for learning/knowledge building purposes), has now been extended to all small schools in one Quebec school district, and is being considered for adoption by all school districts as an alternative to the closing of small elementary schools. This governance decision will likely bring the creation of a coordination/facilitation structure under CEFRIO's leadership. 
Laval University researchers will likely continue to engage in collaborative research with RNS participants. Whether this institutionalization effort will succeed is yet to be seen, but it is important to note that the agency for this effort mainly comes from the school boards rather than those directly involved in the innovation at the school level.

\subsubsection{From a Successful Context-Based Organizational Structure to Its 'Decontextualization'}

For instance, after learning about the government support given by the Hong Kong government to fund half-time secondment of experienced knowledge building teachers to coordinate and organize professional development for more teachers under a university-school partnership scheme, the Catalunya government also proceeded to the establishment of teacher coordinators for their KB network and created secondment positions.

\subsubsection{From a Government-Led Innovation towards a Teacher-Coordinated Innovation Network}

In Catalunya, KBIP was a government-led innovation. It is now on the verge of becoming a teacher-coordinated innovation network with the collaboration of the Col-legi de Doctors i Llicenciats en Filosofia i Lletres i en Ciències. The appointment of seconded teacher coordinators in the past year formalized the coordination and prepared participants for the transition as school-based teachers and principals have taken increased responsibilities in the professional development of local colleagues, and in the KB international network.

\section{Discussion}

In the KB international network, the affordances of new technology (Web, KF, desktop videoconferencing) prompted participants to seek collaboration within and beyond the boundaries of their local sites. Technology was an agent of change, and so was KBIP as an innovative design supported by collaborative technologies.

Regarding Banathy's first dimension of design (Patterns of interaction, Question 1), the six characteristics of the relationships between agents from within and across educational systems that stood out were the following ones: voluntary participation, distributed leadership, onsite/online communication, cohesion (knowledge building pedagogy), interdependence, and resilience. Evolving patterns of interaction were repeatedly observed. Information exchange, the first of the four patterns that connected participants, was almost unidirectional at the beginning, became multidirectional as participants gained experience in the network. Cooperation increased as the number of classrooms engaging in collaborative inquiry on climate change enlarged and as experienced teachers inducted new participants into the network. Coordination increasingly became the focus of university- and government-based personnel's time and energy. Integration was fostered through participants' co-design of the knowledge building curriculum activities on climate change and sustainability. Local classroom-based and online learning integrated with the asynchronous and synchronous collaboration online. Participants in KBIP, who were only a fraction of the members of the knowledge building community at each of the three sites, were also connected with the larger knowledge building community at the international level through summer institutes. There is self-organization and co-evolution in this community as local partnerships and agents develop socio-technical designs that fit their cultural contexts.

As for the second dimension (Focus of inquiry, Question 2), we found increased agency at each level of the system: learning, teaching, administration and governance. Teachers released agency to students, school administrators released teachers' agency, and governance of the curriculum offered some flexibility at the levels below demonstrating the ecological nature of their hierarchical relationships. The focus of agency kept changing as participants (agents) operated in a condition of flux. There were technology issues (access), but these were nothing compared to student background issues (e.g., language), teacher culture issues (e.g. teaching beliefs), administrative issues (e.g., time management), accountability and governance issues (e.g. curricular requirements) prevailing at local sites that the KB international network had to deal with. Most models of change emphasize "design by external agents and implementation by teachers". We found very little evidence of the validity of the adoption model of change, not only because there was no "model" or "desired practice" to follow since each situation was different and in a state of flux, but also because the change required was not just at the classroom practice level, but also at deeper and wider levels - such as beliefs in the nature of knowledge, how learning takes place, how such change needs to happen in teachers, students and leadership in their schools and beyond, as well as beliefs and practice in the area of accountability and governance at all levels of the education system.

The analysis of the third dimension (Scope of inquiry, Question 3) showed that agents were active within and beyond the boundaries of their existing systems. There was co-evolution through interaction of the agents within and across sites. Originally, the invitation came from a system (university or ministry of education) part of the local (networked) environment. The knowledge building approach had been tested and "proved" to be workable in various situations (e.g. classrooms tend to meet/exceed mandated curricula (Scardamalia and Bereiter, 1994; van Aalst and 
Chan, 2007)). It presents cases and experiences that become useful resources for professional development. The mediating role of school leaders was essential. For a teacher wanting to try out the new approach, s/he cannot succeed by simply "adopting" or replicating what has been done by others. There is a need for innovation on the teacher's part in the entire process, and the agency from the teacher for bringing about change is still necessary. But without the contribution of credible institutions and school principals' support, there is reasonable doubt that the innovation would take hold, evolve, and sustain (see Hew and Brush, 2007). However, an element of risk remains in such a process (Law, 2006). To reduce the risk, research results provided for informed decision-making. Artifacts resulting from collaborative inquiries were made visible to the local communities. Dynamic interaction within and beyond local systems allowed participants to share the risk and the excitement. Extending their agency, they broadened the scope of the inquiry by considering issues and concerns arising in their ecological environment and beyond. Boundary spanning was obvious.

Bottom-up and top-down (vertical) processes are often advocated as critical for change to occur. We observed lateral processes as well: For instance, teachers exchanged ideas regarding the release of collective agency to students, a process often found difficult by many teachers (Scardamalia and Bereiter, 2006). Our data analysis suggests a model of change that brings a much wider diversity of practices than many curriculum innovation initiatives focused around specific pedagogical designs - resulting in an ecological collection of practices. The assumption behind traditional models of change and implementation based on a model of diffusion, i.e. with the goal of building replicates of exemplars or best practices, is challenged by the above results. Much effort has been invested in studying how specific innovations can be "institutionalized" (Anthony, Johnson, and Sinfield 2008; Legters, Balfanz, Jordan, and McPartland, 2002). We suggest that "institutionalization" is not something that can be achieved as a one-off "solution" to implement and sustain innovation. First of all, in any school, the "innovators" are necessarily few. As the process of innovation progresses, an increased tension between the innovators and the rest of the professional community in the school often emerges. Even with leadership support, there may be increased tension, though its ways of manifesting itself may differ. Often, institutionalization might become "withdrawals" of significant conditions, such that established changes may become "endangered". In our present study, teachers found their participation to be focused tightly in a local professional community, one linked to an international network devoted to the advancement of a specific frame of understanding, and also found related practices to be a very important source of professional, social and emotional support. In particular, the collaboration between cross-national classrooms facilitated professional cross-fertilization, visibility of the innovation in a socially recognized format and, in some cases, reduced the sense of professional isolation when there were no other teachers sharing the same pedagogical vision in their immediate professional environment. These collaborations became boundary objects for intra- and cross-national interaction and collaboration at all levels of the education system, bringing about changes in learning, teaching, administration and governance through processes of self-organization rather than replication or implementation of an external design.

\section{Conclusion}

Complex systems and their components seek evolution through interaction as pointed out by Prigogine and Stengers (1984). It is the potential to extend and enhance social interaction that drew one of the co-authors of this paper to the use of Internet-based collaborative technologies, and related research. But interactivity is not enough, as pointed by Collins and Halverson (2009, p. 32) by reaffirming Cuban's (1986) statement that technological innovation must take into account routines and organization of schools.

Our working hypothesis is that an ecological model of change is more adaptable and adaptive than change instituted as "initiatives". This study brings evidence that an ecological model of change creates conditions that are conducive to sustainability. Lieberman (2000) has argued for the value of teacher networks. In the KBIP project, we have documented the "ecological role" of an international network in the change process. We have focused on the agency demonstrated by participants as they developed socio-technical designs for engaging students in collaborative inquiry and knowledge building on climate change related themes. There is a strong sense among all participants of this international network that it is important to understand how other people operate as an integral part of the knowledge building process. We have evidence of agency and deep learning exhibited variously by different groups of stakeholders at different times in different sites. This network model of self-organization and change actually works! It is not piecemeal change, not revolutionary, not top-down. It is gradual, and evolutionary. Participants have the space and the opportunity to learn from one another, and each component to actually self-organize, to be more compatible. The most important point is that real change at the bottom, classroom level is fostered, strengthened and appropriated, achieving our goal of sustainability and scalability for knowledge building as a pedagogical innovation! 
While we have reasonable confidence that this innovation will be sustainable, we are aware that it is still fragile. The $\mathrm{KB}$ international network is nothing compared to fast growing technology-based social networks like Facebook or Twitter. The engagement of new teachers is slow. How will the participation of new teachers progress through time? Will it survive any withdrawal of support?

Our model is based on partnerships (university, school, government) interested in renewing formal learning environments building on advances made from the knowledge building perspective. University-based researchers and graduate students as well as school-based teachers work in a tightly knitted network with their local government support. We see a need for dynamic interaction and simultaneous self-organizing change at all levels for sustainable innovation. Educational researchers from a variety of perspectives could make theoretical and practical advances using a similar systemic model.

Future research steps will seek to identify other key environmental features that nurture/sustain change and study in greater depth the dynamics of the interactions within and across each of the three dimensions of inquiry in Banathy's model. It is our hope that these new developments will enrich our understanding of the model of ecological change that we have begun to describe.

\section{References}

Anthony, S. D., Johnson, M. W., \& Sinfield, J. V. (Eds.) (2008). Institutionalizing innovation. Special issue of MITSloan Management Review, 49(2), 44-54.

Axelrod, R., \& Cohen, M. D. (1999). Harnessing complexity: Organizational implications of a scientific frontier. New York: The Free Press.

Banathy, B. H. (1991). Systems design of education: A journey to create the future. Englewood Cliffs, NJ: Educational Technology Publications.

Bereiter, C., \& Scardamalia, M. (2003). Learning to work creatively with knowledge. In E. D. Corte, L. Verschaffel, N. Entwistle, \& J. V. Merriënboer (Eds.), Powerful learning environments: Unravelling basic components and dimensions (pp. 73-78). Oxford: Elsevier Science.

Collins, A., Joseph, D., \& Bielaczyc, K. (2004). Design research: theoretical and methodological issues. Journal of the Learning Sciences, 13(1), 15-42. http://dx.doi.org/10.1207/s15327809jls1301_2

Engeström, Y. (1987). Learning by expanding. An activity-theoretical approach to developmental research. Helsinki: Orienta-Konsultit.

Engeström, Y. (2001). Expansive learning at work. Toward an activity-theoretical reconceptualization, Journal of Education and Work, 14(1), 133-156.

Hew, K. F., \& Brush, T. (2007). Integrating technology into K-12 teaching and learning: current knowledge gaps and recommendations for future research. Educational Technology Research and Development, 55, 223-252. http://dx.doi.org/10.1007/s11423-006-9022-5

Hutchins, E. (1995). Cognition in the wild. Cambridge, MA: MIT Press.

Hutchins, C. L. (1994). State systems of education and systemic change. In C. M. Reigeluth \& R. J. Garfinkle (Eds.), Systemic change in education (pp. 15-25). Englewood Cliffs, NJ, USA: Educational Technology Publications.

Kaptelinin, V., \& Nardi, B. (2006). Acting with technology: Activity theory and interaction design. Cambridge, MA: MIT press.

Laferrière, T., \& Lamon, M. (2010). Knowledge Building / Knowledge Forum ${ }^{\circledR}$ : The transformation of classroom discourse. In M. S. Khine and I. M. Saleb, (Eds.), New Science of Learning: Cognition, computers and Collaboration in Education (pp. 485-502). New York: Springer.

Laferrière, T., Montane, M. Gros, B., Alvarez, I., \& Bernaus, M., et al. (2010). Partnerships for Knowledge Building: An Emerging Model. Second special edition on knowledge building, edited by M. Scardamalia \& B. Egnetoff, Canadian Journal of Learning Technologies, 36(1), 1-20.

Laferrière, T., Hamel, C., Allaire, S., Turcotte, S., Breuleux, A., Beaudoin, J., \& Gaudreault-Perron, J. (2011). L'école éloignée en réseau: L'apprentissage des élèves. Rapport-synthèse, CEFRIO, Québec.

Law, N. (2006, March 26-30, 2006). Supporting Bricolage as Leadership for Systemic Pedagogical Innovations. Paper presented at the Society for Information Technology and Teacher Education Annual Conference, Orlando, Florida, USA 
Law, N., Yuen, J., Wong, W., \& Leng, J. (2011). Understanding learners' knowledge building trajectory through visualizations of multiple automated analyses. In S. Puntambekar, G. Erkens \& C. Hmelo-Silver (Eds.), Analyzing Interactions in CSCL: Methodologies, Approaches and Issues. pp. 47-82. New York: Springer. http://dx.doi.org/10.1007/978-1-4419-7710-6_3

Legters, N. E., Balfanz, R., Jordan, W. J., \& McPartland, J. M. (2002). Comprehensive reform for urban high schools: A talent development approach. New York: Teachers College Press.

Lemke, J. L., \& Sabelli, N. H. (2008). Complex systems and educational change: Towards a new research agenda. Educational Philosophy and Theory, 40(1), 118-129. http://dx.doi.org/10.1111/j.1469-5812.2007.00401.x

Lieberman, A. (2000). Networks as learning communities: Shaping the future of teacher development. Journal of Teacher Education, 51(3), 221-227. http://dx.doi.org/10.1177/0022487100051003010

Nonaka, I., \& H. Takeuchi (1995). The knowledge-creating company. New York: Oxford University Press.

Prigogine, I., \& Stengers, I. (1984). Order out of chaos: Man's new dialogue with nature. New York: Bantam.

Scacchi, W. (2004). Socio-technical design. In W. S. Bainbridge (Ed.), The encyclopedia of human-computer interaction (pp. 656-659). Great Barrington, MA: Berkshire Publishing Group.

Scardamalia, M., \& Bereiter, C. (1994). Computer support for knowledge-building communities. The Journal of the Learning Sciences, 3, 265-283. http://dx.doi.org/10.1207/s15327809jls0303_3

Scardamalia, M., \& Bereiter, C. (2004). Knowledge Building. In Encyclopedia of Education, Second Edition. New York: Macmillan Reference.

Scardamalia, M., \& Bereiter, C. (2006). Knowledge building: Theory, pedagogy and technology. In R. K. Sawyer (Ed.), The Cambridge handbook of learning sciences (pp. 97-115). New York: NY: Cambridge University Press.

Scardamalia, M., Bransford, J. Kozma, B., \& Quellmalz, E. (2010). Draft white paper 4: New assessments and environments for knowledge building. ATC21S. Australia: University of Melbourne. [Online] Available: http://atc21s.org/wp-content/uploads/2011/11/4-Environments.pdf (January 25, 2011)

van Aalst, J., \& Chan, C. K. K. (2007). Student-directed assessment of knowledge building using electronic portfolios. The Journal of the Learning Sciences, 16(2), 175-220. http://dx.doi.org/10.1080/10508400701193697

Table 1. KBIP Online Participants (2007-2009)

\begin{tabular}{|l|l|l|l|l|l|l|}
\hline Sites & Students & Teachers & $\begin{array}{l}\text { School } \\
\text { Principals }\end{array}$ & $\begin{array}{l}\text { Ministry } \\
\text { Personnel }\end{array}$ & $\begin{array}{l}\text { Graduate } \\
\text { Students }\end{array}$ & $\begin{array}{l}\text { University } \\
\text { researchers }\end{array}$ \\
\hline Catalunya & 500 & 20 & 11 & 3 & 1 & 2 \\
\hline Hong Kong & 300 & 12 & 2 & 1 & 4 & 3 \\
\hline Quebec & 300 & 18 & 4 & 1 & 4 & 3 \\
\hline
\end{tabular}

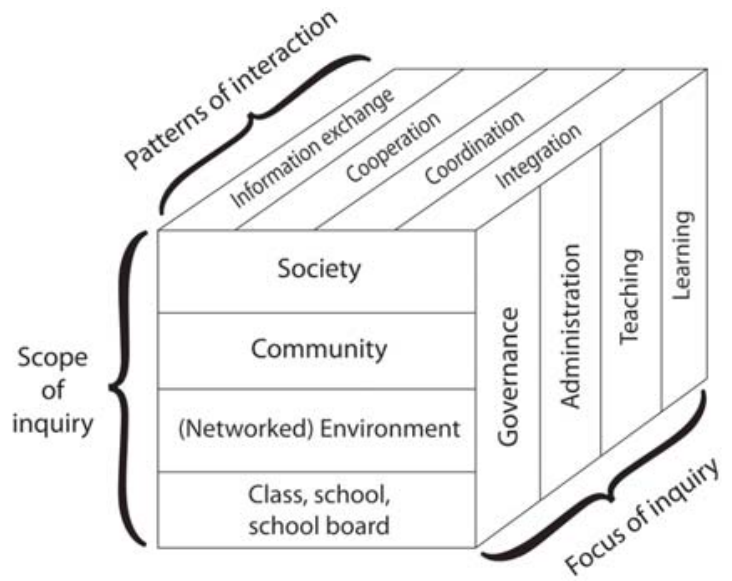

Figure 1. Adaptation of Banathy’s dimensions for systemic educational design 